\title{
Improving nutritional accuracy and economics through a multiple ration-grouping strategy
}

\author{
Jorge A. Barrientos-Blanco, Heather White, 주 Randy D. Shaver, and Victor E. Cabrera* $₫$ \\ Department of Dairy Science, University of Wisconsin-Madison, Madison 53705
}

\begin{abstract}
The objective of this study was to develop a model application to systematize nutritional grouping (NG) management in commercial dairy farms. The model has 4 sub-sections: (1) real-time data stream integration, (2) calculation of nutritional parameters, (3) grouping algorithm, and (4) output reports. A simulation study on a commercial Wisconsin dairy farm was used to evaluate our NG model. On this dairy farm, lactating cows $(\mathrm{n}=2,374 \pm 185)$ are regrouped weekly in 14 pens according to their parity and lactation stage, for which 9 diets are provided. Diets are seldom reformulated and nutritional requirements are not factored to allocate cows to pens. The same 14 pens were used to simulate the implementation of NG using our model, closely following the current farm criteria but also including predicted nutritional requirements (net energy for lactation and metabolizable protein; $\mathrm{NE}_{\mathrm{L}}$ and $\mathrm{MP}$ ) and milk yield in an attempt to generate more homogeneous groups of cows for improved diet accuracy. The goal of the simulation study was to implement a continuous weekly system for cows' pen allocation and diet formulation. The predicted $\mathrm{MP}$ and $\mathrm{NE}_{\mathrm{L}}$ requirements from the NG were used to formulate the diets using commercial diet formulation software and the same feed ingredients, feed prices, and other criteria as the current farm diets. Diet $\mathrm{MP}$ and $\mathrm{NE}_{\mathrm{L}}$ densities were adjusted to the nutritional group requirements. Results from the simulation study indicated that the NG model facilitates the implementation of an NG strategy and improves diet accuracy. The theoretical diet cost and predicted nitrogen supply with NG decreased for lownutritional-requirement groups and increased for highnutritional-requirement groups compared with current farm groups. The overall average $\mathrm{N}$ supply in diets for
\end{abstract}

Received September 18, 2019.

Accepted December 11, 2019.

*Corresponding author: vcabrera@wisc.edu
NG management was $15.14 \mathrm{~g} /$ cow per day less than the current farm grouping management. The average diet cost was $\$ 3,250 /$ cow per year for current farm management and $\$ 3,219 /$ cow per year for NG, which resulted in a theoretical $\$ 31 /$ cow per year diet cost savings.

Key words: feed cost, diet accuracy index, nutritional grouping, real-time data integration

\section{INTRODUCTION}

Nutritional grouping (NG) management can improve the nutritional accuracy of diets, reduce nutrient losses, and increase income over feed costs (IOFC) in dairy farms (Cabrera et al., 2012; Kalantari et al., 2016; Wu et al., 2019). Available on-farm data streams, computer and feeding systems, and existing farm grouping (FG) protocols offer an opportunity to facilitate the implementation of NG.

Grouping lactating cows into multiple pens is a common practice in dairy farms (Robinson, 2003; Contreras-Govea et al., 2015). Nevertheless, nutritional requirements are not usually considered for grouping cows (Contreras-Govea et al., 2015). In a survey of dairy farms in Wisconsin and Michigan, Contreras-Govea et al. (2015) reported that parity, DMI, maintaining full pens, and milk yield are the principal factors used for grouping cows. They also reported that one of the main reasons to minimize the number of rations for lactating cows was the desire to keep feeding management simple.

Nutritional grouping yields groups of cows with more homogeneous nutritional requirements. This facilitates better allocation of diet nutrients and therefore dietary nutritional accuracy (Kalantari et al., 2016; Barrientos et al., 2018; Bach, 2019). Dietary nutritional accuracy can be defined as feeding cows closer to their nutritional requirements (Cerosaletti and Dewing, 2008). If dietary nutritional accuracy is low, the proportions of underfed and overfed cows increase (Kalantari et al., 2016; Bach, 2019). Underfed cows suffer from underconditioning, which decreases milk productivity and reproductive performance (Roche et al., 2009, 2013). In contrast, 
overfed cows suffer from overconditioning (Kalantari et al., 2016), which increases the risk of metabolic disorders in the next lactation (Cameron et al., 1998; Roche et al., 2009).

Better nutritional accuracy would increase milk productivity and reduce nutrient excretion (Kalantari et al., 2016). Maltz et al. (2013) demonstrated that feeding individual diets that match the nutritional requirements of a cow could increase milk yield by 3.3 $\mathrm{kg} /$ cow per day compared with a single group diet in early-lactation cows. In contrast, decreasing $\mathrm{CP}$ and RUP concentrations of diets of mid- and late-lactation cows did not affect milk production but did reduce $\mathrm{N}$ excretion (Kalscheur et al., 1999).

Better nutritional accuracy of NG would also reduce overall feed costs (Kalscheur et al., 1999; VandeHaar et al., 2016) and increase IOFC (Kalantari et al., 2016; Wu et al., 2019). Multiple NG simulation analyses have shown productive and economic benefits when lactating cows are grouped according to their nutritional requirements (St-Pierre and Thraen, 1999; Allen, 2009; Bach, 2014; Kalantari et al., 2016). Nevertheless, there is no currently available application that could help dairy farmers systematically implement NG. Likewise, there is no application to collect, integrate, manage, and analyze dairy farm data to support improvements in decision-making process related to farm management (Liang et al., 2018) such as NG. The development of a model that collects, integrates, and analyzes relevant continuous data streams could provide an opportunity to implement NG in a practical, efficient, and accurate way on dairy farms.

To fill these technological gaps and address the need to improve the nutritional accuracy of diets and farm profitability, this study provides an innovative mathematical model designed to facilitate the implementation of NG in commercial dairy farms. The model was tested with a simulation study applied to a commercial dairy farm.

\section{MATERIALS AND METHODS}

Research was performed following 2 main steps: (1) developing a prescriptive model for implementing $\mathrm{NG}$ strategies in dairy farms; and (2) evaluating the developed model by a simulation analysis with data from a commercial dairy farm, a simulation study. Analyses and model development were built under the RStudio programming language environment (version 3.5.3; https://www.r-project.org/).

\section{Prescriptive Model Development}

The model was developed to systematize NG management in commercial dairy farms. The model has 4 sub-sections: (1) real-time data stream integration, (2) nutritional parameter calculations, (3) grouping algorithm, and (4) output reports.

\section{Data Integration}

This sub-section was designed to import and combine data from different data sources of a farm. It involved cleaning up potential unknown characters of the merging reference variables using the "str_replace_all" function in RStudio. All continuous data from the feeding, and cow's profile recording systems were merged to a single data set using file date, cow ID, and (or) group ID as merging reference variables. The integrated data set is stored in an Excel file (Microsoft Corp., Redmond, WA) and used later for calculating the nutritional parameters. The required data variables to run the nutritional grouping model are specified in Table 1. All observations are in number format except the date. This data integration is prepared to automatize the uptake of different data streams to generate required inputs for implementing NG management without supervision on a weekly or monthly interval, according to farm goals.

Table 1. Data variables required by the nutritional grouping model for the simulation study

\begin{tabular}{|c|c|c|c|c|}
\hline Data source $^{1}$ & Variable & Definition & Unit & Variable objective \\
\hline
\end{tabular}

${ }^{1}$ DC305 (Dairy Comp 305) and FeedComp are from Valley Agricultural Software (Tulare, CA). 


\section{Nutritional Parameter Calculations}

Deterministic nutritional parameters for DMI (kg of $\mathrm{DM} /$ cow per day), $\mathrm{NE}_{\mathrm{L}}$ (Mcal/cow per day), and MP (g/cow per day) are calculated based on NRC (2001) equations. These parameters are in function of $\mathrm{BW}$, milk yield, milk protein and fat contents, and DIM.

$B W$. Because of the limited availability of BW records in dairy farms, the model includes an algorithm to calculate the daily individual cow's BW according to average herd BW by parity and stage of lactation following Kalantari et al. (2016). Average BW for primiparous and multiparous were used as reference to calculate the inflexion BW changes at 42 and 336 DIM for primiparous animals and at 63 and 336 DIM for multiparous animals following Kalantari et al. (2016).

$D M I$. The predicted daily $D M I_{i}$ per cow $i$ was calculated as a function of $B W_{i}, F C M_{i}$, and week of lactation (WOL $L_{i}$; NRC, 2001):

$$
\begin{aligned}
D I_{i} & =\left(0.372 \times F C M_{i}+0.0986 \times B W_{i}^{0.75}\right) \\
& \times\left[1-e^{[-0.192 \times(W O L+3.67)}\right],
\end{aligned}
$$

where $F C M_{i}$ is the fat-corrected milk per cow $i\left(F C M_{i}\right.$ $=0.4 \times$ milk yield $+15 \times$ milk yield $\left.\times\left(C P_{\text {milk }} / 100\right)\right]$ and $B W_{i}$ is the predicted $\mathrm{BW}$ for cow $i$. The calculated $D M I_{i}$ were adjusted to have the same average as the actual pen DMI. Actual pen DMI is the total consumed DM $(\mathrm{kg} / \mathrm{pen})$ calculated as supplied DM $(\mathrm{kg} / \mathrm{pen})$ minus the total orts $(\mathrm{kg} / \mathrm{pen})$. To adjust the individual cow's $D M I_{i}$, the actual DMI average per pen was divided by the calculated average $D M I_{i}$ per pen, and the result was multiplied by the individual cow's $D M I_{i}$.

Net Energy. Total $N E_{L i}(\mathrm{Mcal} /$ cow per day) requirement per cow $i$ was calculated in function of net energy for maintenance $\left(N E_{M i}\right)$, net energy for milk production $\left(N E_{L i}\right)$, and net energy for gain $\left(N E_{G i}\right.$ (all in Mcal/ cow per day), which were calculated from NRC (2001) equations $11-3,2-16$, and 11-2, respectively.

$M P$. Total $M P_{i}$ (g/cow per day) requirement per cow $i$ was calculated in function of MP for maintenance $\left(M P_{M i}\right), \mathrm{MP}$ for milk production $\left(M P_{L i}\right)$, and MP for gain $\left(M P_{G i}\right)$ (all in $\mathrm{g} / \mathrm{cow}$ per day), which were calculated from the equations on page 68 of NRC (2001).

Diet Accuracy Index. To measure the nutritional accuracy of the diets, we developed a diet accuracy index (DAI). The DAI contrasts the nutrient requirement versus the nutrient offered in the diet and is calculated as an absolute value. Diet accuracy is inversely related to the magnitude of the calculated DAI value; as the nutritional accuracy of the diet increases, the DAI value gets closer to zero:

$$
\text { DAI.NE } E_{P E N}=\frac{\sum_{i=1}^{n_{P E N}}\left|\frac{\operatorname{Diet}_{N E_{P E N}}}{\operatorname{ActualDMI}_{P E N}}-\frac{N E_{i}}{D M I_{i}}\right|}{n_{P E N}}
$$

and

$$
D A I . M P_{P E N}=\frac{\sum_{i=1}^{n_{P E N}}\left|\frac{\operatorname{Diet} M P_{P E N}}{A c t u a l D M I_{P E N}}-\frac{M P_{i}}{D M I_{i}}\right|}{n_{P E N}},
$$

where DAI.NE $E_{P E N}$ is the DAI for $\mathrm{NE}_{\mathrm{L}}$ and DAI.MPPEN is the DAI for MP in the pen. The $\mathrm{NE}_{\mathrm{L}}$ supplied by the diet assigned to pen is $\operatorname{Diet} N E_{P E N}$, and $N E_{i}$ is the calculated $\mathrm{NE}_{\mathrm{L}}$ requirement for cow $i$ allocated to pen (Mcal/cow per day). The MP supplied by the diet assigned to a pen is DietMP $P_{P E N}$ and $M P_{i}$ is the calculated MP requirement for cow $i$ allocated to pen (g/cow per day); $n_{P E N}$ is the number of cows in the analyzed pen.

\section{NG Algorithm}

Kalantari et al. (2016) used a ranking method to aggregate cows according to their $\mathrm{MP}$ and $\mathrm{NE}_{\mathrm{L}}$ requirements as a proxy of the clustering method proposed by McGilliard et al. (1983). We followed that approach but, unlike Kalantari et al. (2016), we kept our model flexible to first accommodate possible farm group requirements such as state of lactation (postpartum, early, peak, late lactation), parity, or milk yield. After the cows are grouped, the model provides a list of cows for each nutritional group, which depends on the size and number of nutritional groups.

Setting the Size and Number of Nutritional Groups. The number of cows per group is constrained by the maximum allowed number of cows per pen, whereas the number of nutritional groups is limited by the farm goals, which are defined by the farm decisionmaker.

Categorizing Parity and Stage of Lactation Variables. Dairy farmers may want to group or maintain groupings of cows according to parity, stage of lactation, (Contreras-Govea et al., 2015) or other criteria. Our model is able to accommodate these forced grouping requirements by using conditional statement functions. Once these are imposed, nutritional grouping is accommodated. 
Algorithm for Grouping Cows Nutritionally. The model is designed to group cows according to continuous variables such as milk yield, $\mathrm{MP}$ and $\mathrm{NE}_{\mathrm{L}}$ requirements, or other potential meaningful variables for nutritionally grouping cows. The first step in this model sub-section is normalizing each continuous variable; the second is summing up the normalized variables per cow (norm); and the third is calculating the percentile rank for each cow using the variable norm. Finally, cows are aggregated in groups by their percentile rank according to the desired number and size of groups.

\section{Movements of Cows Across Groups}

The model tracks the number of cows that are moved in and out of each group by using conditional statements. Therefore, it is possible to quantify the total number of cows moved in each regrouping period and follow the flow of cows in groups and pens across time.

\section{Diet Formulation}

The optimum MP and $\mathrm{NE}_{\mathrm{L}}$ requirements per group (unit/kg of DM) are calculated using a percentile of milk yield distribution method, as suggested by Stallings and McGilliard (1984). Then, the model allows the user to set the desired percentile of the milk yield distribution to be used as a reference value to calculate the optimum $\mathrm{MP}$ and $\mathrm{NE}_{\mathrm{L}}$ requirement per nutritional group. As required by any diet formulation software, the model selects the cow that has the minimum absolute difference to that percentile value. In this section, before this optimum $\mathrm{MP}$ and $\mathrm{NE}_{\mathrm{L}}$ are calculated, $10 \%$ in each tail of the milk yield distribution per group are removed to avoid nonrealistic optimum $\mathrm{MP}$ and $\mathrm{NE}_{\mathrm{L}}$ requirement values that could be generated by outliers.

\section{Simulation Study: Evaluating the NG Model}

A simulation study with data from a large-scale commercial dairy farm of Holstein cows located in Wisconsin was used to evaluate the performance of the proposed model over a 9-wk period. The merged data set included data from DairyComp 305 (DC305; cow management software; Valley Agricultural Software, Tulare, CA) and FeedComp (feed management software; Valley Agricultural Software). Specific information about the data collected from each software is detailed in Table 1. These 2 data streams were merged using the merging function and cleaned using str_replace_all function in RStudio. Pen ID (Pen) and file date (Fdate) were used as reference variables to merge the data sets (Table 1). This simulation study included all healthy, lactating cows at the farm $(\mathrm{n}=2,374 \pm 185$ animals $)$. The

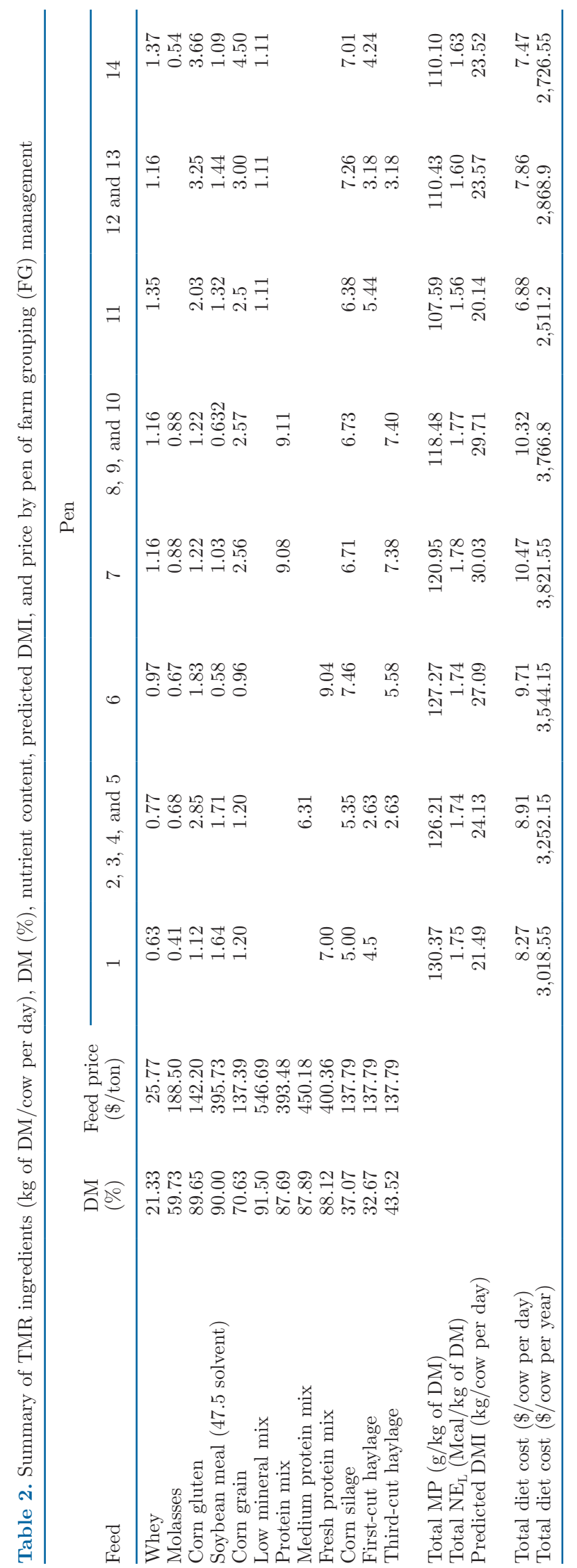


Barrientos-Blanco et al.: DAIRY INDUSTRY TODAY

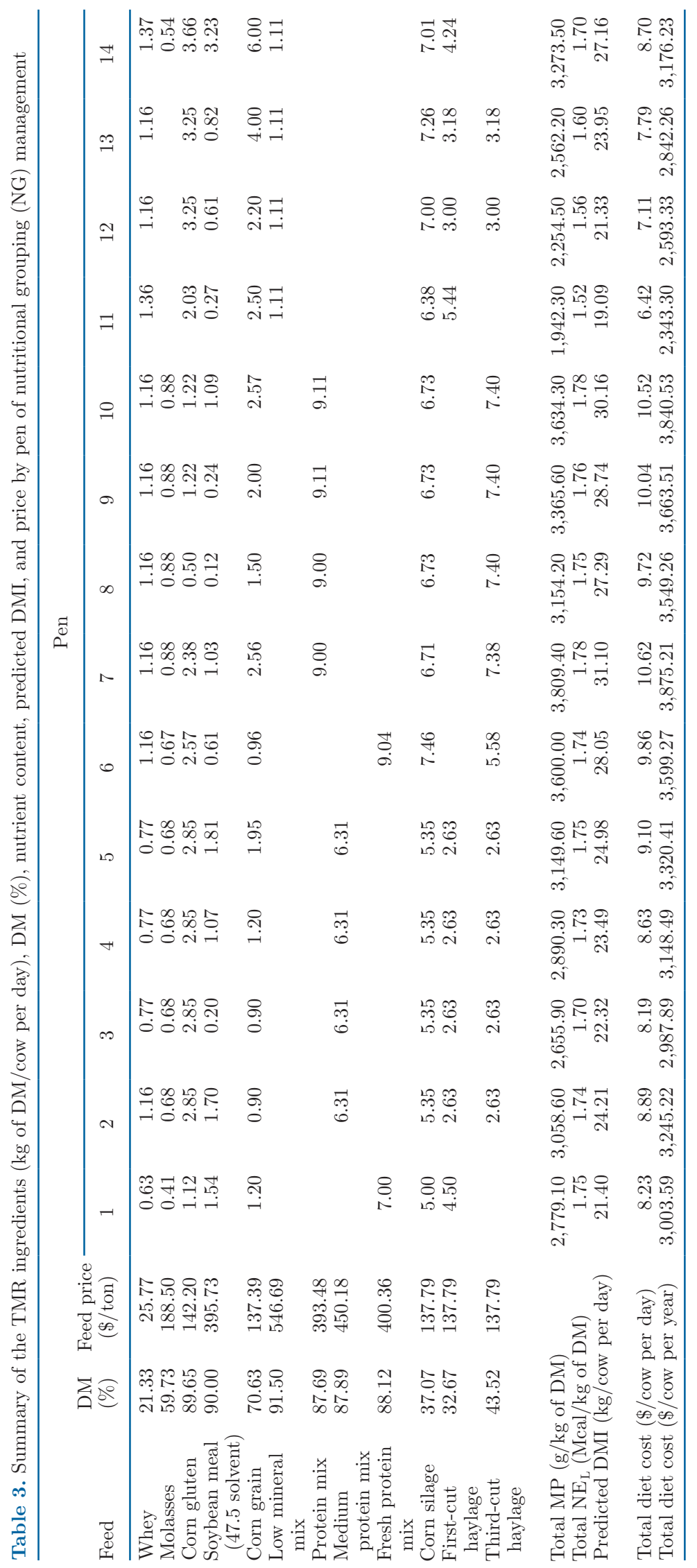


entire group of lactating cows are currently grouped in 14 pens according to their parity (primiparous and multiparous) and stage of lactation (postpartum, early, peak, and late lactation) for which 9 diets are provided. They use the nutritional dynamic systems (NDS) diet formulation software for diet formulation and diet costs (Table 2). The farm diets are reformulated a few times a year and nutritional requirements are not used as criteria to allocate cows across pens. Cows are regrouped every week on Tuesdays during the night shift. The decision of which cows are moved in each group is made by the farm manager. A report with a list of cows, pen number, stage of lactation, and parity is printed from DC305 and, based on this information, the farm manager decides which cows to move. The weekly regrouping process is made by sorting cows using electronic automatic gates and cows' radiofrequency ID (RFID) but requires employee supervision and correction.

Following farm practice, the model was run every week to allocate cows to groups, first by parity and DIM, and then by $\mathrm{NE}_{\mathrm{L}}, \mathrm{MP}$, and milk yield. Cows were allocated to the 14 pens and a diet was reformulated for each pen. Diets for all groups and for FG and NG were formulated using the same NDS software of the farm and based on the predicted MP (main constraint) and $\mathrm{NE}_{\mathrm{L}}$ (secondary constraint) requirements per group (Table 2 and Table 3 ). These requirements were predicted following the "83rd percentile of milk yield" method suggested by McGilliard et al. (1983). Consistent with farm practice, the average of the weekly diets per pen was used for all 9 wk of simulation analysis. Hence, the diet in each pen remained constant for both FG and NG during the study period. The same farm diet ingredients were used to formulate diets for the FG and NG strategies (Table 2 and Table 3 ).

\section{RESULTS AND DISCUSSION}

\section{Grouping Cows}

Different from FG practice, our NG model uses predicted $\mathrm{MP}$ and $\mathrm{NE}_{\mathrm{L}}$ requirements and milk yield as grouping criteria, in addition to parity and stage of lactation categories. As depicted in Table 4, the same lactation, DIM, and stage categories were further classified in different milk yield and diet-requirement pens. For example, in the peak multiparous groups, pen 8 has the lowest, pen 9 has intermediate, and pen 10 has the highest milk yield (Table 4), which results in low, medium, and high $\mathrm{MP}$ and $\mathrm{NE}_{\mathrm{L}}$ predicted requirements, respectively. Different nutrient allocations for 3 nutritional groups are consistent with results previously reported by Kalantari et al. (2016) and Wu et al. (2019).

Our NG model kept the desired number of cows per simulated pen fixed over time, which removed the potential risk of over- or understocking cows in the simulated pens (Table 5). The number of simulated nutritional groups per parity and stage of lactation category is consistent with the number of nutritional groups recommended in several studies (Cabrera et al., 2012; St-Pierre and Weiss, 2015; Kalantari et al., 2016). However, these depend on the farm facility design and farmer goals.

In the simulation study, as expected, the NG model showed better allocation of cows by parity (primiparous

Table 4. Milk yield and DIM ( \pm SD) of cows allocated to pens on farm grouping (FG) and nutritional grouping (NG) management

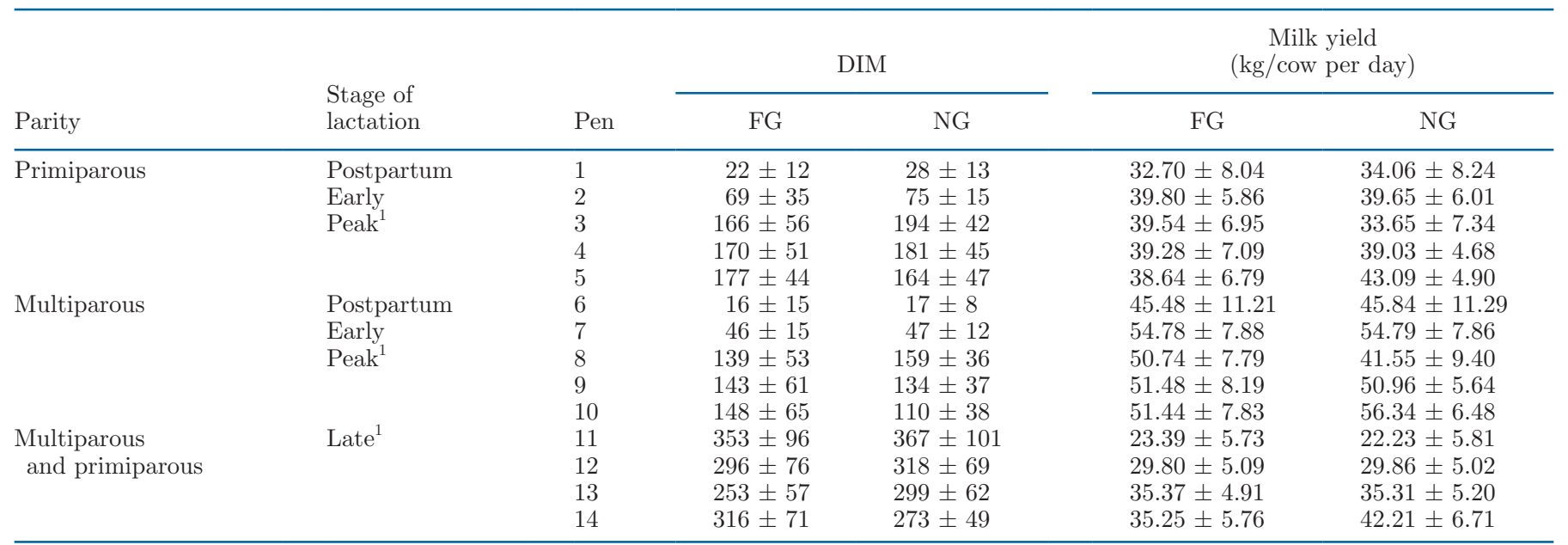

${ }^{1}$ Groups of cows that were aggregated into 3 (primiparous and multiparous in peak lactation) or 4 groups (primiparous and multiparous in late lactation) according to their $\mathrm{MP}$ and $\mathrm{NE}_{\mathrm{L}}$ requirements. 
and multiparous) and stage of lactation (postpartum, early, peak, and late lactation). As observed in Figure 1, FG management resulted in parity and DIM misclassifications (Figure 1A and 1B) of cows in different stages: postpartum (pen 1 for primiparous and pen 6 for multiparous), early (pen 2 for primiparous and 7 for multiparous), peak (pens 3, 4, and 5 for primiparous cows and pens 8, 9, and 10 for multiparous), and late lactation (pens 11, 12, 13, and 14 for primiparous and multiparous cows).

The number of cows moved across pens is an important factor to consider when implementing NG management. As expected, the model calculated greater movements for NG in simulated pens that had the opportunity of applying nutritional groups (pens $3,4,5,8,9,10,11,12,13$, and 14; Table 5). This is due to the natural changes in the predicted nutritional requirements and milk yield of the cows throughout lactation. One concern of dairy farmers with increasing the movement of cows across groups is the potential decrease in milk yield after moving (Contreras-Govea et al., 2015). Nevertheless, Zwald and Shaver (2012) reported that increasing the number of cows' movements among groups does not decrease significantly milk yield if group sizes are larger than 100 cows.

\section{Nutritional Accuracy}

The simulation study showed improvements in the theoretical nutritional accuracy of the diet due to better allocation of nutrients among simulated pens with NG management. As observed in Table 6, the 14 groups of lactating cows currently on the farm are fed with 9 different diets. The peak- and late-lactation groups (primiparous and multiparous) are each fed with a single diet. However, each of these has its own diet with NG. The use of NG management facilitates the allocation of nutrients through the formulation of diets with greater nutritional accuracy (Cabrera and Kalantari, 2016). This fact is proven by the lower NG DAI.MP and DAI.NE reported in Table 6 and their fewer variable distributions (Figure 2). High variability of predicted requirements was expected and seen with FG because there is no nutritional allocation, which constrains the possibility of improving the nutritional accuracy of the offered diets. Even though simulated pens for peak- and late-lactation cows are aggregated based on their predicted nutritional requirements, some simulated pens still show large variability because of the presence of cows with extreme low or high predicted nutritional requirements due to the imposed FG criteria and the constraint of maintaining constant pen size. Because diets for the simulation study were formulated using predicted MP as the main requirement constraint and

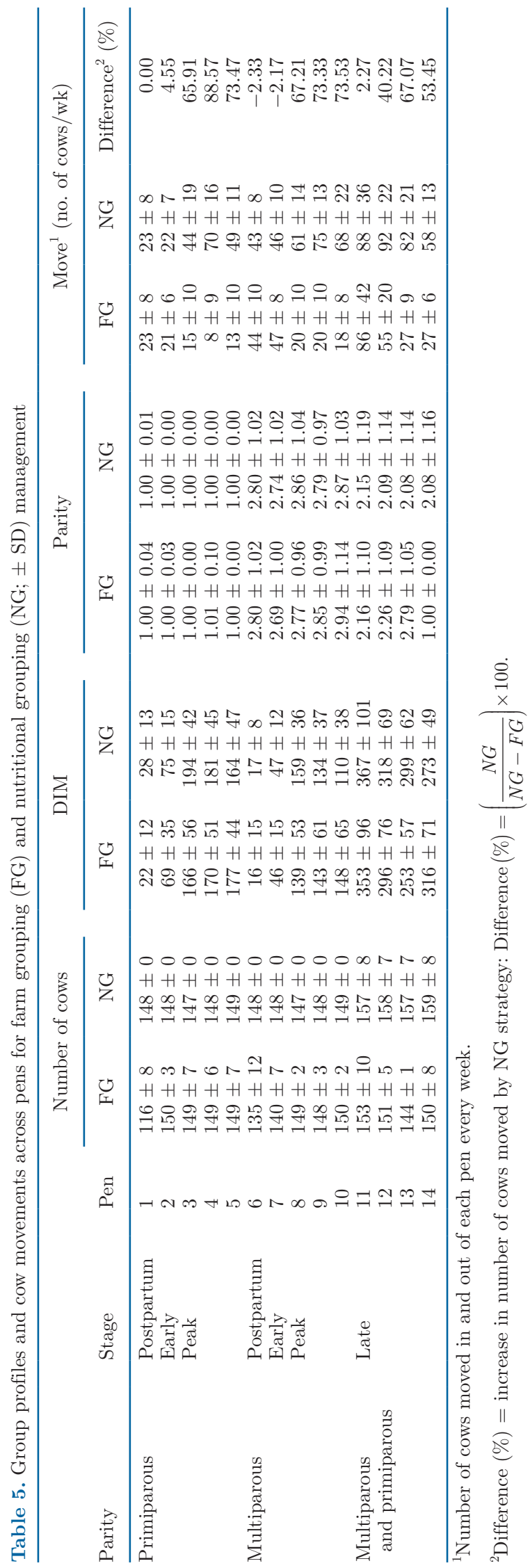



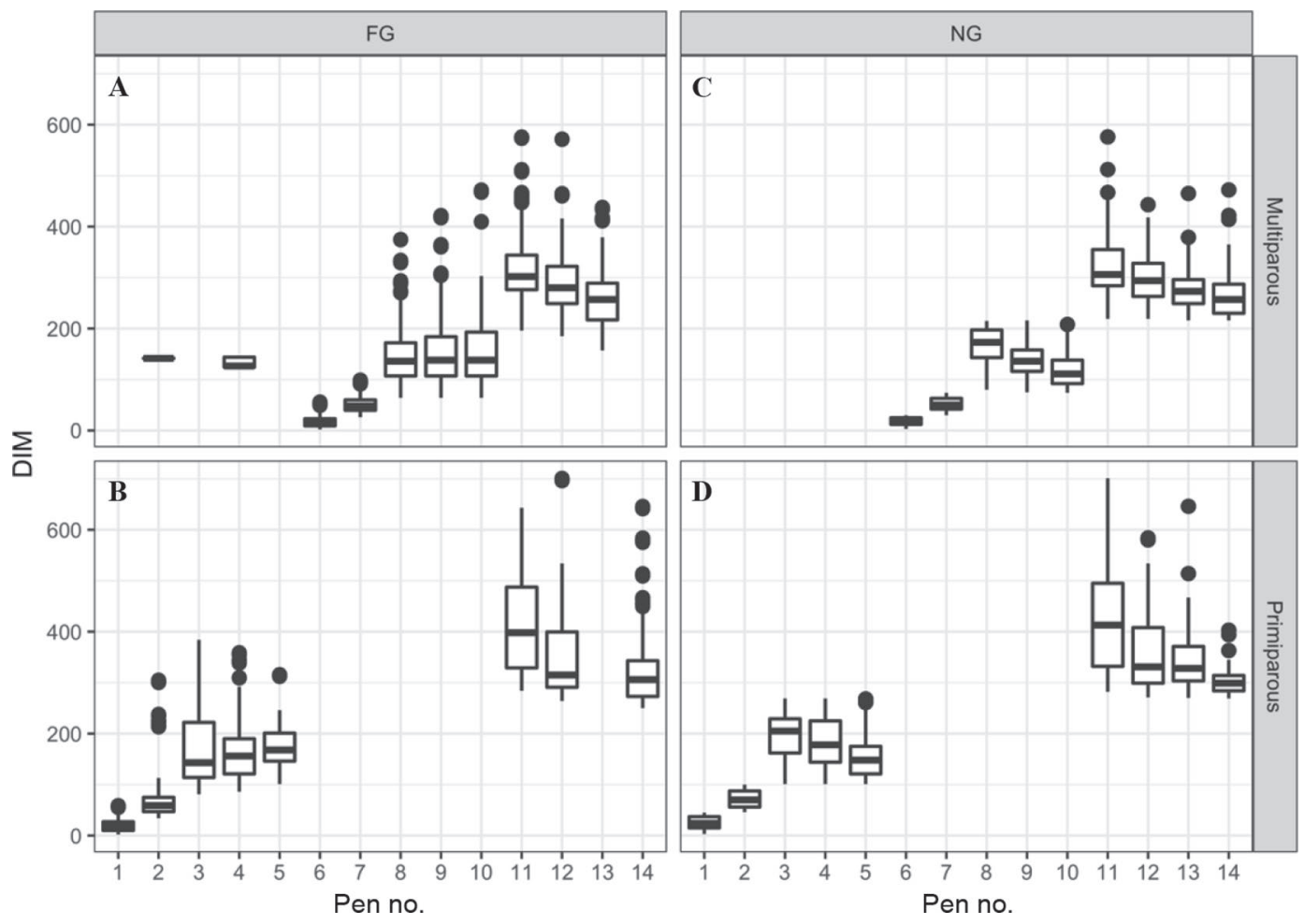

Figure 1. Boxplots for DIM of cows in different pens: (A) multiparous cows in farm grouping (FG), (B) primiparous cows in FG, (C) multiparous cows in nutritional grouping $(\mathrm{NG})$, and $(\mathrm{D})$ primiparous cows in NG. Box $=$ second and third quartile; midline $=$ median; lower whisker $=$ first quartile; upper whisker $=$ fourth quartile; dots $=$ outliers.

predicted $\mathrm{NE}_{\mathrm{L}}$ as the secondary requirement constraint, greater improvement in theoretical DAI.MP than DAI. NE was expected and found (Table 6).

In addition, DAI.MP and DAI.NE can be improved by increasing the frequency of formulating diets as suggested by White and Capper (2014). Once the NG model is adopted by farm management, pen diets could be adjusted weekly according to ever-changing cow requirements assigned to pens for even greater accuracy.

\section{Environmental Benefits of NG Management}

Better theoretical nutritional accuracy of the diets using NG management results in less nutrient losses of predicted $\mathrm{N}$ supplied by the diets, to the benefit of the environment (White and Capper, 2014). The predicted $\mathrm{N}$ supplied from diets with the NG strategy $(711.21 \pm 99.23)$ was $15.14 \mathrm{~g} / \mathrm{cow}$ per day lower, hypothetically, than with FG management (726.35 \pm 65.94; Table 7). The total decrease in annual predicted $\mathrm{N}$ supplied by the diets was 13.12 tons for the average lactating herd size of 2,374 cows. As observed in Table 7 , groups of cows for the NG strategy with low and medium predicted nutritional requirements (pens 3,4 , $8,9,11,12$, and 13 in Table 4) have diets that supply lower predicted $\mathrm{N}$, whereas groups of cows with high nutritional requirements (pens 5, 10, and 14) have diets that supply greater predicted $\mathrm{N}$ than the diets for $\mathrm{FG}$ management.

\section{Economics of NG Management}

The improvement of dietary nutrition accuracy may generate economic benefits from the potential increase in milk yield (Kalscheur et al., 1999; Maltz et al., 2013; Kalantari et al., 2016) and savings from a decrease in diet costs (Cabrera and Kalantari, 2016; Kalantari et al., 2016; Wu et al., 2019). In this research, we did not predict potential milk yield improvement from the NG strategy. Thus, the economic benefits related to the potential increase of milk yield were not considered in the economic analysis. Hypothetical economic benefits reported here are due only to savings from decreased diet costs. With the exception of pens 2, 5, 6, 7, 10, and 14, all other diets showed lower diet costs (Table 8). The most significant increase in diet cost for NG was in pens for postpartum and early-lactation multiparous cows (pens 6 and 7), which is related to the effect of grouping cows by parity and stage of lactation following farm protocol. Simulated pens 6 and 7 show an in- 
crease in the predicted MP density of the diets for NG compared with FG management (Table 6). Simulated pens 5,10 , and 14 show a greater cost of diets because of the NG management effect. These pens house the cows that have the highest milk yield and predicted nutritional requirements. Thus, the adjustment in the diets to a greater predicted $\mathrm{MP}$ and $\mathrm{NE}_{\mathrm{L}}$ supply increased the cost of the diets compared with the diets of FG management. Most of the increase in diet cost was related to the predicted $\mathrm{CP}$, which is the most expensive nutrient of a diet (St-Pierre and Thraen, 1999). Overall, the potential average cost of the diets across all simulated pens was $\$ 31 /$ cow per year less for the NG strategy than for current FG management. These savings in predicted diet costs are mostly due to the savings generated by nutritional groups (pens 3, 4, $8,9,11,12$, and 13). Our results are consistent with those of other studies. Kalantari et al. (2016) found that NG management increased IOFC by $\$ 39 \pm 6$ for 3 nutritional groups and by $\$ 46 \pm 7$ for 4 nutritional groups. They reported that the main drivers for increasing IOFC were the increase in milk yield and lower feed cost. The decrease in feed cost was mainly related to the decrease in predicted MP concentration in the diet. Wu et al. (2019) and St-Pierre and Thraen (1999) reported an average IOFC increase of $\$ 71$ and $\$ 76.65$ / cow per year, respectively, when using 3 diets instead of only 1 diet.

\section{Implications of NG Management Implementation}

The NG strategy is an application designed to systematize the implementation of NG management in dairy farms. It allows a dairy farmer or farm manager to (1) integrate data streams from feeding and cow profile recording systems; (2) group cows according to nutritional requirements in addition to predefined farm criteria such as parity or stage of lactation; (3) calculate the optimum nutritional requirements per group; and (4) formulate group diets accordingly. The systematization of grouping cows could help dairy farmers decrease the time and errors in the decision-making process of grouping cows. Less time and fewer errors could decrease the labor time and costs, overstocking cows in pens, and misplaced cows. Importantly, implementing NG management creates more homogeneous groups of cows in terms of nutritional requirements. These groups would facilitate better allocation of nutrients in diets and therefore improve the herd's nutritional accuracy. Although not implemented and tested in this study, improved nutritional accuracy through NG may result in greater milk yield (not included in this study), less overconditioned cows (not included in this study), lower negative environmental impacts due to decreased

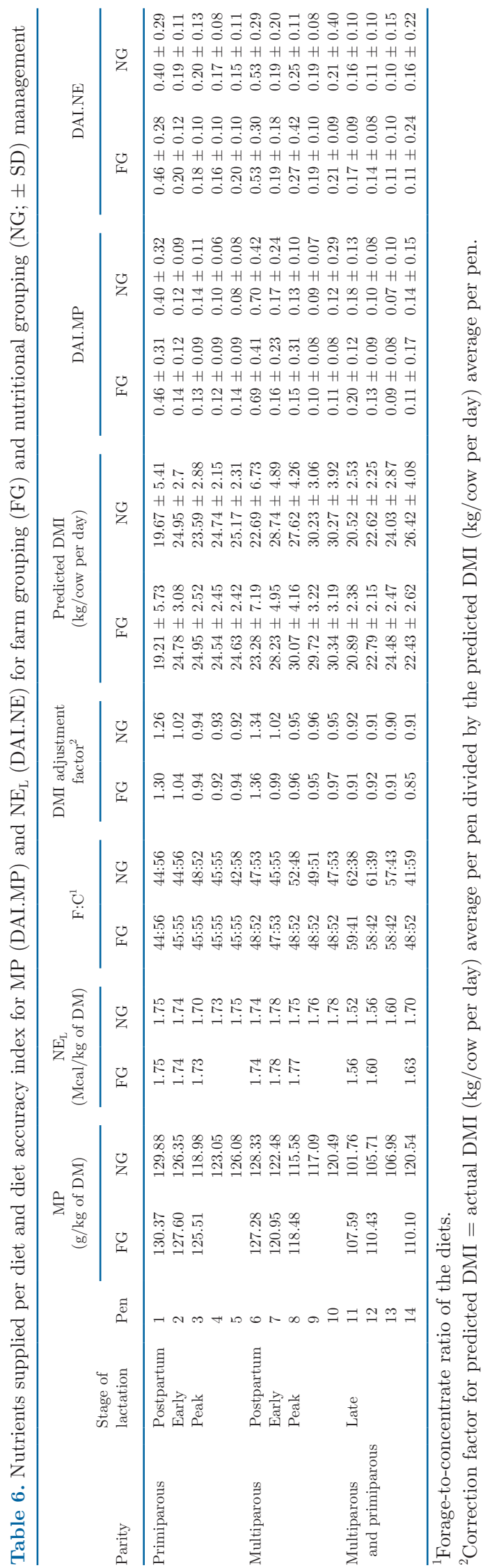


Table 7. Total nitrogen supplied per diet (N) for farm grouping (FG) and nutritional grouping (NG) management

\begin{tabular}{|c|c|c|c|c|c|}
\hline \multirow[b]{2}{*}{ Parity } & \multirow[b]{2}{*}{$\begin{array}{l}\text { Stage of } \\
\text { lactation }\end{array}$} & \multirow[b]{2}{*}{ Pen } & \multicolumn{3}{|c|}{$\mathrm{N}(\mathrm{g} /$ cow per $\mathrm{d})$} \\
\hline & & & FG & NG & $\begin{array}{c}\text { Difference } \\
(\mathrm{NG}-\mathrm{FG})\end{array}$ \\
\hline \multirow[t]{5}{*}{ Primiparous } & Postpartum & 1 & 672.62 & 664.71 & -7.91 \\
\hline & Early & 2 & 742.53 & 736.94 & -5.59 \\
\hline & Peak & 3 & 720.51 & 609.18 & -111.33 \\
\hline & & 4 & & 684.37 & -36.14 \\
\hline & & 5 & & 754.80 & 34.29 \\
\hline \multirow[t]{5}{*}{ Multiparous } & Postpartum & 6 & 770.99 & 805.75 & 34.76 \\
\hline & Early & 7 & 819.57 & 863.80 & 44.23 \\
\hline & Peak & 8 & 788.64 & 699.93 & -88.71 \\
\hline & & 9 & & 749.13 & -39.51 \\
\hline & & 10 & & 826.29 & 37.65 \\
\hline \multirow{4}{*}{$\begin{array}{l}\text { Multiparous } \\
\text { and primiparous }\end{array}$} & Late & 11 & 578.04 & 491.53 & -86.51 \\
\hline & & 12 & 693.94 & 600.53 & -93.41 \\
\hline & & 13 & & 655.66 & -38.28 \\
\hline & & 14 & 625.13 & 819.90 & 194.77 \\
\hline
\end{tabular}

\section{(A) DAI for MP}

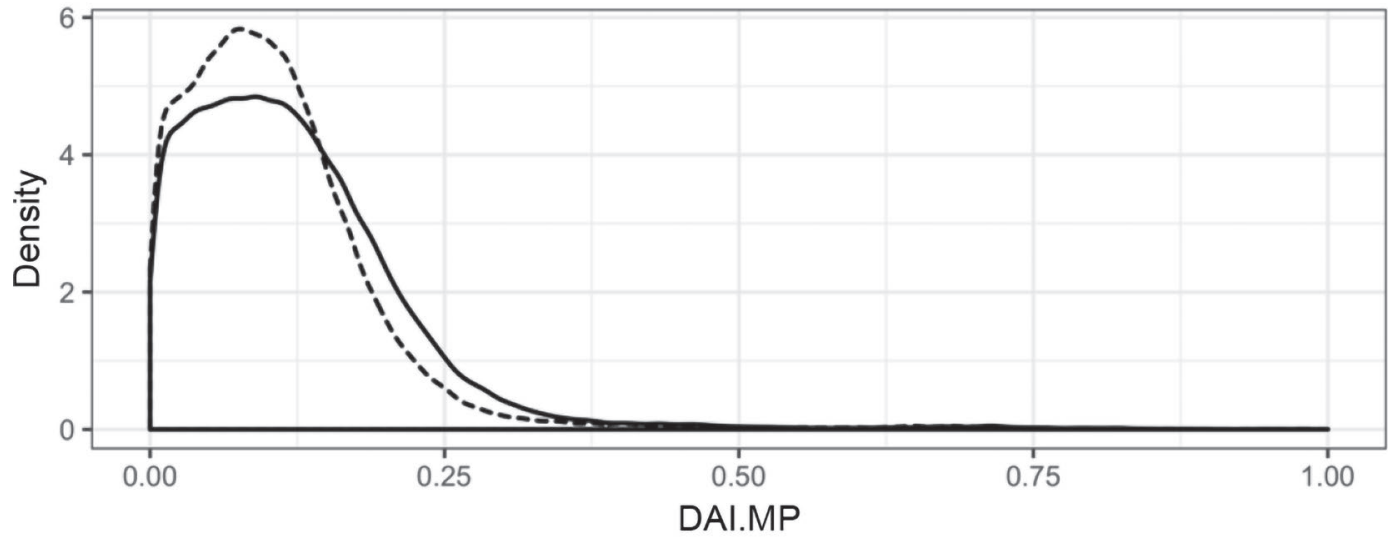

(B) DAl for $\mathrm{NE}_{\mathrm{L}}$

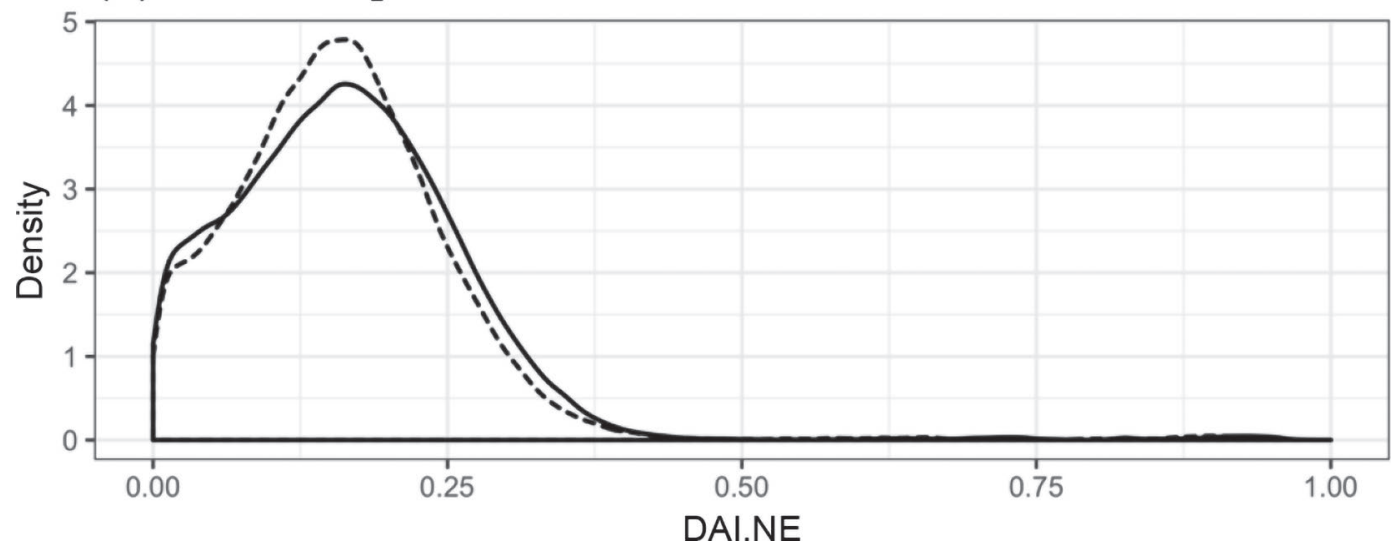

Figure 2. Statistical distribution of diet accuracy index for MP (DAI.MP) and NE $\mathrm{L}_{\mathrm{L}}$ (DAI.NE) for farm grouping (FG, solid line) and nutritional grouping (NG; dashed line) management. 
Table 8. Comparative economic analysis between farm grouping (FG) and nutritional grouping (NG; \pm SD) management

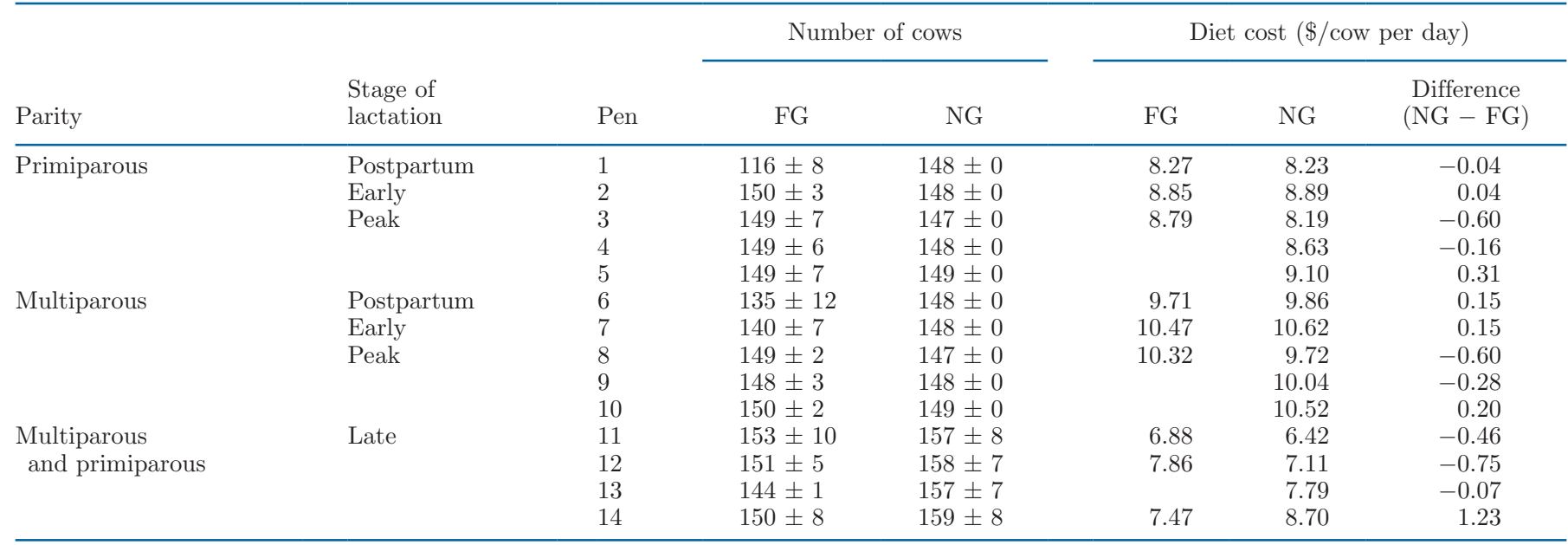

nutrient losses, increased milk income (not included in this study), and decreased diet costs. These potential benefits from the NG strategy should be further examined in future on-farm grouping studies.

\section{Limitations of the Model and the Study}

Because of the lack of parameterization data, the simulation analysis did not predict the cow's production performance in response to formulated diets for NG and FG strategy. On-farm field trials of NG strategies are required to measure the quantitative effect of NG management in milk yield. We speculate, however, that milk production will increase in our NG because this strategy better aligns the nutrients supplied in the diets to the requirements of the cows. This benefit is yet to be included in NG.

Even though the NG model is flexible enough to be implemented in commercial dairy farms, it still requires farm-specific adjustments to accommodate each farm's specific data and software recording systems. Also, the application requires a user-friendly interface to facilitate its use and application.

The economic analysis did not consider the additional cost for NG management related to increasing the number of diets, such as nutritionist service time to formulate more diets and labor time to load, mix, and distribute the diets. Extra labor time, equipment, and machinery required for additional diets are factors that need to be measured and considered in the economic analysis. Further on-farm validation studies can provide the information required to account for the extra costs. Nonetheless, based on previous studies, we speculate that the additional costs will be small compared with the benefits and would not diminish the value of applying an NG strategy on dairy farms (Kalantari et al., 2016).

\section{CONCLUSIONS}

The simulation study demonstrated the theoretical advantages of implementing NG strategies on dairy farms. Application of our model could decrease the errors related to misplacing cows or missing cow movements to a different group. The NG model decreased the time required to create a list of cows to be allocated to pens and reduced the risk of under- and overcrowding pens. In addition, the NG model showed better allocation of cows to simulated pens according to predicted nutritional requirements. Importantly, our nutritional grouping management improved diet accuracy. This improvement resulted in lower predicted $\mathrm{N}$ supply in benefit of the environment. Average predicted N supply with simulated nutritional grouping management was lower by $15.14 \mathrm{~g} / \mathrm{cow}$ per day. Our proposed NG management resulted in potential economic benefits from diet cost savings. The simulation study suggests that implementing NG management may result in a theoretical $\$ 31 /$ cow per year greater IOFC due to potential diet cost savings. In addition, the economic benefits of NG management would be greater if the potential increases in milk productivity when applying NG management were accounted for. A future research goal is to measure the effect of NG management in milk productivity using on-farm trials.

\section{ACKNOWLEDGMENTS}

This project was supported by the University of Wisconsin-Madison UW2020 initiative to the project 
titled "A Virtual Dairy Farm Brain: The Next Big Leap in Dairy Farm Management Applying Artificial Intelligence"; the USDA-NIFA-FACT (Washington, DC) grant 2019-68017-29935 to project titled "Developing a Dairy Brain: The Next Big Leap in Dairy Farm Management Using Coordinated Data Ecosystems"; and Hatch Project no. WIS01849 to V. E. Cabrera and R. D. Shaver. The lead author thanks Liliana FadulPacheco and Hector Delgado (University of Wisconsin, Madison) and Di Liang (Zoetis, Florham Park, NJ) for their contribution to this work. The authors have not stated any conflicts of interest.

\section{REFERENCES}

Allen, M. S. 2009. Grouping to increase milk yield and decrease feed costs. Pages 61-65 in Proc. Tri-State Dairy Nutr. Conf., Ft. Wayne, IN. The Ohio State University, Columbus.

Bach, A. 2014. Precision feeding to increase efficiency for milk production. West. Can. Dairy Semin. Adv. Dairy Technol. 26:177-189.

Bach, A. 2019. Decomposing efficiency of milk production and maximizing profit. J. Dairy Sci. 102(Suppl. 1):397. (Abstr.)

Barrientos, J. A., É. Chabonneau, S. Binggeli, and V. E. Cabrera. 2018. Improving nutritional accuracy and economics through multiple ration-grouping strategy. Pages 1-58 in Proc. Symp. sur les bovins laitiers, Drummondville, Québec, Canada. Centre de Référence en Agriculture et Agroalimentaire du Québec (CRAAQ), Quebec, Canada.

Cabrera, V. E., F. Contreras, R. D. Shaver, and L. Armentano. 2012. Grouping strategies for feeding lactating dairy cattle. Pages 13 14 in Proc. Four-State Dairy Nutrition and Management Conf., Dubuque, IA.

Cabrera, V. E., and A. S. Kalantari. 2016. Economics of production efficiency: Nutritional grouping of the lactating cow. J. Dairy Sci. 99:825-841. https://doi.org/10.3168/jds.2015-9846.

Cameron, R. E., P. Dyk, T. Herdt, J. Kaneene, R. Miller, H. Bucholtz, J. Liesman, M. Vandehaar, and R. Emery. 1998. Dry cow diet, management, and energy balance as risk factors for displaced abomasum in high producing dairy herds. J. Dairy Sci. 81:132-139. https://doi.org/10.3168/jds.S0022-0302(98)75560-2.

Cerosaletti, P., and D. Dewing. 2008. What is precision feed management? Pages $15-16$ in Proc. Northeast Dairy Producers, Ithaca, NY.

Contreras-Govea, F. E., V. E. Cabrera, L. E. Armentano, R. D. Shaver, P. M. Crump, D. K. Beede, and M. J. VandeHaar. 2015. Constraints for nutritional grouping in Wisconsin and Michigan dairy farms. J. Dairy Sci. 98:1336-1344. https://doi.org/10.3168/ jds.2014-8368.

Kalantari, A. S., L. E. Armentano, R. D. Shaver, and V. E. Cabrera. 2016. Economic impact of nutritional grouping in dairy herds. J. Dairy Sci. 99:1672-1692. https://doi.org/10.3168/jds.2015-9810.

Kalscheur, K. F., J. Vandersall, R. Erdman, R. Kohn, and E. RussekCohen. 1999. Effects of dietary crude protein concentration and degradability on milk production responses of early, mid, and late lactation dairy cows. J. Dairy Sci. 82:545-554. https://doi.org/10 $.3168 /$ jds.S0022-0302(99)75266-5.
Liang, D., H. Delgado, and V. E. Cabrera. 2018. A Virtual Dairy Farm Brain. Pages 1-19 in Proc. 13th European IFSA Symp. International Farming Systems Association (IFSA) Europe, Crete, Greece.

Maltz, E., L. Barbosa, P. Bueno, L. Scagion, K. Kaniyamattam, L. Greco, A. De Vries, and J. Santos. 2013. Effect of feeding according to energy balance on performance, nutrient excretion, and feeding behavior of early lactation dairy cows. J. Dairy Sci 96:5249-5266. https://doi.org/10.3168/jds.2013-6549.

McGilliard, M. L., J. M. Swisher, and R. E. James. 1983. Grouping lactating cows by nutritional-requirements for feeding. J. Dairy Sci 66:1084-1093. https://doi.org/10.3168/jds.S0022-0302(83)81905 -5 .

NRC. 2001. Nutrient Requirements of Dairy Cattle. 7th rev. ed. The National Academies Press, Washington, DC.

Robinson, P. 2003. Grouping strategies for dry and lactating dairy cows-The Southwest experience. West. Can. Dairy Semin. 15:171179.

Roche, J. R., N. C. Friggens, J. K. Kay, M. W. Fisher, K. J. Stafford, and D. P. Berry. 2009. Invited review: Body condition score and its association with dairy cow productivity, health, and welfare. J. Dairy Sci. 92:5769-5801. https://doi.org/10.3168/jds.2009-2431.

Roche, J. R., K. A. Macdonald, K. E. Schütz, L. R. Matthews, G. A. Verkerk, S. Meier, J. J. Loor, A. R. Rogers, J. McGowan, S. R. Morgan, S. Taukiri, and J. R. Webster. 2013. Calving body condition score affects indicators of health in grazing dairy cows. J. Dairy Sci. 96:5811-5825. https://doi.org/10.3168/jds.2013-6600.

St-Pierre, N. R., and C. S. Thraen. 1999. Animal grouping strategies, sources of variation, and economic factors affecting nutrient balance on dairy farms. J. Anim. Sci. 77(Suppl_2):72-83.

St-Pierre, N. R., and W. P. Weiss. 2015. Partitioning variation in nutrient composition data of common feeds and mixed diets on commercial dairy farms. J. Dairy Sci. 98:5004-5015. https://doi .org/10.3168/jds.2015-9431.

Stallings, C. C., and M. L. McGilliard. 1984. Lead factors for total mixed ration formulation. J. Dairy Sci. 67:902-907. https://doi .org/10.3168/jds.S0022-0302(84)81386-7.

VandeHaar, M. J., L. E. Armentano, K. Weigel, D. M. Spurlock, R. J. Tempelman, and R. Veerkamp. 2016. Harnessing the genetics of the modern dairy cow to continue improvements in feed efficiency. J. Dairy Sci. 99:4941-4954. https://doi.org/10.3168/jds .2015-10352.

White, R. R., and J. L. Capper. 2014. Precision diet formulation to improve performance and profitability across various climates: Modeling the implications of increasing the formulation frequency of dairy cattle diets. J. Dairy Sci. 97:1563-1577. https://doi.org/ 10.3168/jds.2013-6859.

Wu, Y., D. Liang, R. D. Shaver, and V. E. Cabrera. 2019. An income over feed cost nutritional grouping strategy. J. Dairy Sci. 102:4682-4693. https://doi.org/10.3168/jds.2018-15302.

Zwald, A., and R. Shaver. 2012. Case study: Effect of pen change on milk yield by dairy cows in 2 commercial herds. Prof. Anim. Sci. 28:569-572. https://doi.org/10.15232/S1080-7446(15)30407-1.

\section{ORCIDS}

Heather White () https://orcid.org/0000-0001-5449-2811

Victor E. Cabrera ( https://orcid.org/0000-0003-1739-7457 